\title{
Audiological implications of COVID-19: an integrative literature review
}

Georgea Espindola Ribeiro'

https://orcid.org/0000-0003-3969-5252

Daniela Polo Camargo da Silva ${ }^{2}$

https://orcid.org/0000-0003-2082-9361
Universidade Estadual Paulista - UNESP, Faculdade de Medicina de Botucatu, Departamento de Oftalmologia, Otorrinolaringologia e Cirurgia Cabeça e Pescoço, Botucatu, São Paulo, Brasil.

Universidade Federal de Santa Catarina UFSC, Departamento de Fonoaudiologia, Florianópolis, Santa Catarina, Brasil.

Conflict of interests: Nonexistent

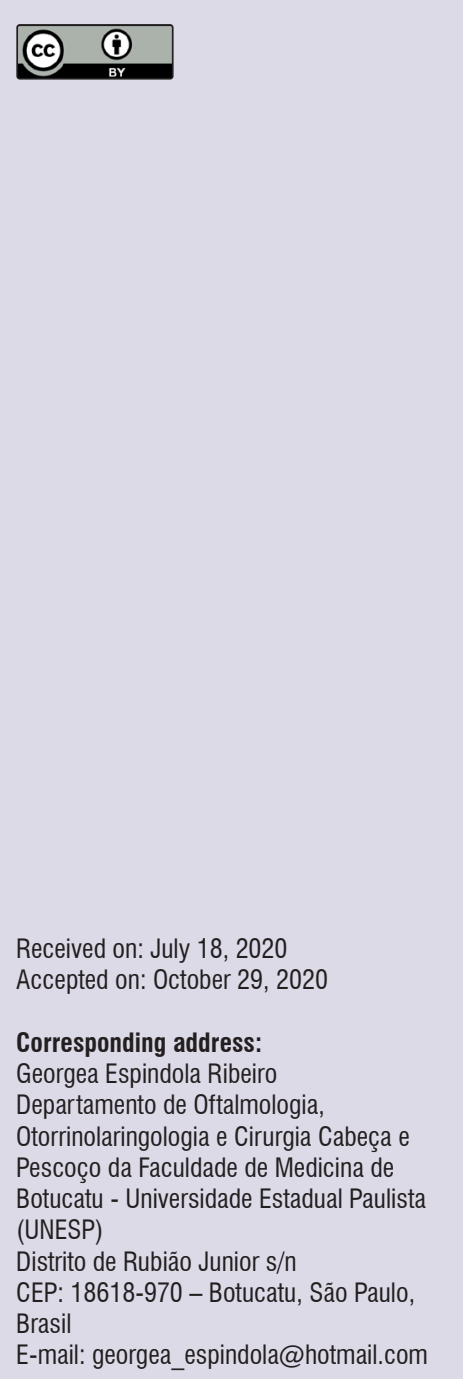

\section{ABSTRACT}

Purpose: to survey the national and international literature on the impacts of the coronavirus infection on the auditory system.

Methods: an integrative review with search in the BIREME, PubMed, Scopus, and Web of Sciences databases. Inclusion criteria: articles in Portuguese and English whose subject was the coronavirus infection and its effects on the auditory system. Exclusion criteria: information from books and/or chapters, letters to editors, review articles, experience reports. The search strategy was based on the following combined descriptors, respectively in Portuguese and English: "Infecções por coronavírus", "Audição", "Perda auditiva", "Coronavirus infections", "Hearing", "Hearing Loss".

Results: out of 43 articles found, two approached the issue. The first study assessed 20 patients that tested positive for COVID-19, though asymptomatic, who underwent pure-tone threshold audiometry and otoacoustic emissions. A significant increase in the auditory thresholds at high frequencies and a smaller response amplitude in the transient evoked otoacoustic emissions of those who tested positive for COVID-19 were observed when compared to that of controls. The second study reported the case of an asymptomatic 35-year-old COVID-19 female patient, who complained of otalgia and tinnitus, after being contaminated. The pure-tone threshold audiometry and tympanometry indicated mild unilateral (right ear) conductive hearing loss, with a type B tympanometric curve on that side.

Conclusion: the studies included in this review showed different consequences of COVID-19 on hearing, with possible impairments on the sensory and mechanical structures of the auditory system. The knowledge of COVID-19 is limited, and further studies on its real impact on the auditory system are necessary.

Keywords: Coronavirus Infections; Hearing; Hearing Loss 


\section{INTRODUCTION}

The coronavirus infection (COVID-19) is caused by SARS-CoV-2, an agent that causes a potentially fatal disease, raising great worldwide public health concern ${ }^{1}$. This disease was first identified in Wuhan, Hubei province, China, and then, it spread throughout the world, affecting more than 120 countries $^{2}$.

COVID-19 is one of the main pathogens whose chief target is the human respiratory system. It predominantly affects adults, most of whom with associated cardiovascular diseases and/or diabetes mellitus ${ }^{3}$. The typical symptoms are fever, coughing, dyspnea, myalgia, headaches, pharyngitis, rhinorrhea, chest pain, and diarrhea ${ }^{3,4}$. Nevertheless, most patients have mild symptoms and a good prognosis ${ }^{3}$.

The transmission rates are unknown, although there is evidence that it happens from person to person. Due to the severity of the clinical complications and high contamination rates, COVID-19 was recognized as a pandemic by the World Health Organization on March $11,2020^{5}$. Hence, government authorities throughout the world took social isolation measures to control the number of infected people, with greater attention and focus on the susceptible ones, including children, health professionals, and older adults ${ }^{1-5}$.

Even though COVID-19 is much related to respiratory impairments, studies point out that many of the existing viral infections can also affect the auditory system, oftentimes causing congenital or even acquired, uni- or bilateral sensorineural hearing loss $(\mathrm{HL})$, either progressive or not $^{6}$. Other types of viral infections, besides affecting the inner ear, may damage the auditory system structures responsible for transmitting sounds ${ }^{6-8}$.

Moreover, as COVID-19 is a recent viral disease, it must be investigated whether infected patients, in addition to the already known clinical manifestations, can also have hearing-related disorders among the sequelae.

Thus, to develop this study, the question arose focused on the COVID-19-exposed population - either children, adults, or older adults - to investigate possible changes in the auditory system. It was based on the hypothesis that this new disease can also affect the hearing, especially because its chief target is the upper airways, consequently worsening the infected person's health condition. It may then require mechanical ventilation, hemodialysis, and the use of drugs that may injure the mechanical and sensory structures of the auditory function.

Therefore, the investigation of this disease's possible negative outcomes on hearing will help health professionals (such as otorhinolaryngologists and speechlanguage-hearing therapists) with previous knowledge on this new viral infection's real effects on the auditory system, contributing to better care for infected people.

Hence, to answer the research question, this paper aimed to survey the national and international literature on the impacts of the coronavirus infection on the auditory system.

\section{METHODS}

This study is an integrative review of the literature, designed to gather findings of studies developed with different methodologies. Thus, the revisors can summarize the results without hurting the epistemological filiation of the studies included here.

The integrative literature review was based on the following steps: identification of the problem (the purpose of the review was clearly defined); search in the literature (delimited by keywords, databases, and article selection criteria); and the evaluation and analysis of the resulting data.

The research question was developed with PECO (patient, exposure, comparison, outcomes) as a strategic didactic acronym ${ }^{9}$. Hence, the research question was defined as: "Do coronavirus-infected people have their auditory structures impaired?". In the acronym, $(P)$ is the population (children, adults, and/or older adults), $(E)$ is the exposure to coronavirus infection, $(\mathrm{O})$ is any impairment of the auditory structures. It is important to highlight that, according to the integrative review method proposed, not all elements of the PECO strategy were applied. In this case, the third one ( $C=$ comparison) was not used (Figure 1$)$. 


\begin{tabular}{|c|c|}
\hline & "Do coronavirus-infected people have their auditory structures impaired?" \\
\hline P & Children, adults, or older adults \\
\hline E & Exposure to the coronavirus infection \\
\hline C & Not applicable \\
\hline $\mathbf{0}$ & Impairment of the auditory structures \\
\hline
\end{tabular}

Source: Canto GDL, $2020^{9}$.

Figure 1. Research question developed with the didactic strategy $(P)$ patient, $(E)$ exposure, $(C)$ comparison, $(0)$ outcomes

The studies were sought in July 2020 and to survey the articles in the literature, the main health databases were searched: BIREME, PubMed, Scopus, and Web of Science, as well as the Health Sciences Descriptors (DeCS) and Medical Subject Headings (MeSH). Such databases were selected because they encompass almost the totality of the indexed production in the field of health.

The search strategy combined the following descriptors in Portuguese and English, respectively: "Infecções por coronavírus", "Audição", "Perda auditiva", "Coronavirus infections", "Hearing", "Hearing Loss". To include the established thematic axes, the "OR" and "AND" Boolean operators were used, according to $\mathrm{MeSH} / \mathrm{DeCS}$.

To be included, the studies had to approach themes on coronavirus infection, and this pathogen's possible impacts on the infected patients' auditory system.

The consultation sample was established with the following inclusion criteria: 1) articles published in Portuguese or English; 2) articles with any date of publication; 3) articles published in national and international blind peer-review journals; 4) articles designed as case report studies, case series, cross-sectional studies, case-control, cohort, and randomized clinical trial.

The main reasons to exclude articles from the sample were information from books and/or chapters, description of integrative and systematic literature reviews, and/or meta-analysis, and reflexive article ${ }^{10,11}$.

The instrument developed to extract and analyze the data from the included studies comprised the following items: (1) Does the text approach coronavirus infection? (2) Is the association between this disease and the auditory system pointed out?

The stages involving the extraction and analysis of the results of the primary studies were independently carried out by two groups of reviewers.

The data extracted from the articles were qualitatively analyzed and summarized. Hence, it was possible to observe, count, describe, and classify the data found, and thus gather the knowledge produced on the theme approached in this review. The methodological design of the studies was interpreted with the classification criteria in relation to the degree of recommendation and levels of evidence (from 1 to 5), as proposed by the Oxford Centre for Evidence-based Medicine - Levels of Evidence ${ }^{12}$.

\section{LITERATURE REVIEW}

After identifying the articles, the primary studies were selected following the previously established research question and inclusion criteria.

Altogether, 43 publications were found with the search strategy, of which 18 were in PubMed, seven in BIREME, 13 in Scopus, and five in Web of Science. All the studies initially had their title and abstract evaluated. If the title and abstract were not enough to define the initial selection, the publication was read in full. Also, in the selection stage, the authors met to reach a consensus on the articles selected, thus minimizing the risk of bias. Hence, two articles were selected, both published in 2020 (Figure 2). Their summary is given in Figure 3. 


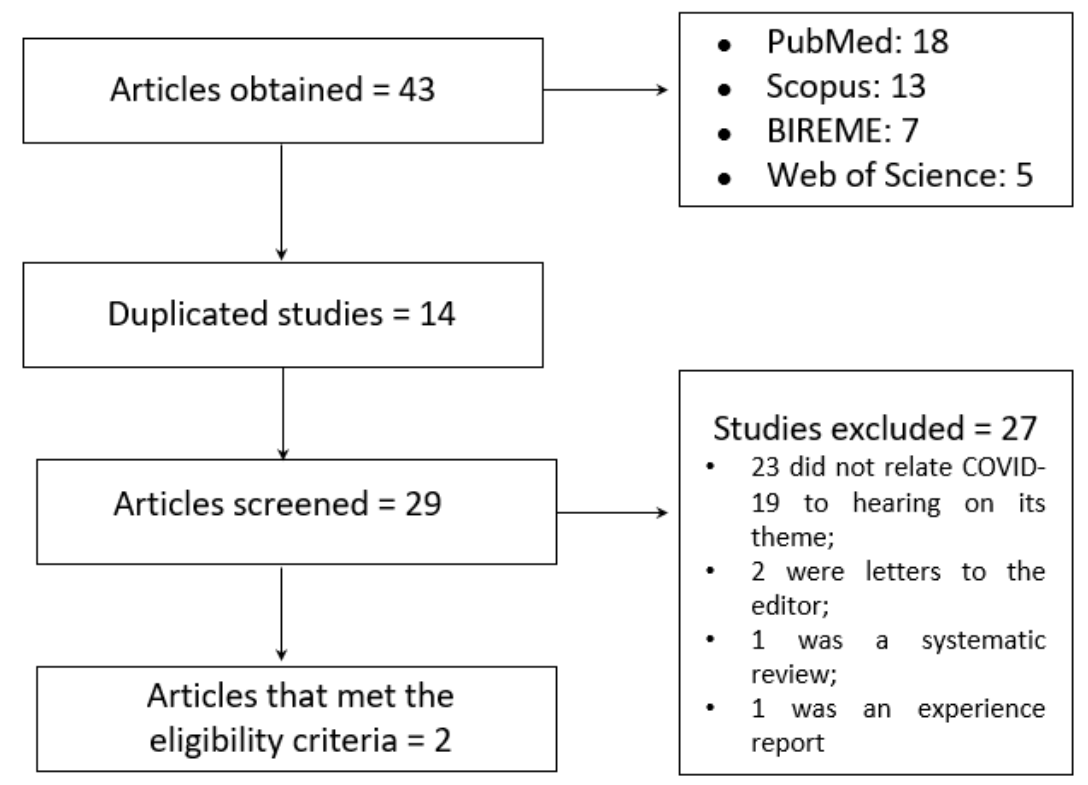

Figure 2. Eligibility of the studies obtained from the databases

\begin{tabular}{|c|c|c|c|c|c|c|}
\hline Study & $\begin{array}{l}\text { Degree of } \\
\text { recommendation } \\
\text { and level of } \\
\text { evidence }\end{array}$ & Country & Type of study & Sample & Main outcomes & Conclusions \\
\hline $\begin{array}{c}\text { Mustafá, } \\
2020^{8}\end{array}$ & $B / 3 B$ & Egypt & Case-control & $\begin{array}{l}20 \text { adult subjects } \\
\text { (20 to } 50 \text { years) who } \\
\text { had asymptomatic } \\
\text { COVID-19 (PCR-RT), } \\
\text { compared with } 20 \\
\text { healthy subjects. }\end{array}$ & $\begin{array}{c}\text { PTA: Larger } \\
\text { audiometric } \\
\text { thresholds in the } \\
\text { subjects with } \\
\text { COVID-19, from } \\
250 \text { to } 8000 \text {, with } \\
\text { statistical significance } \\
\text { at } 4000,6000 \text {, and } \\
8000 \mathrm{~Hz} \text { TEOAE: } \\
\text { The mean response } \\
\text { amplitude was } \\
\text { significantly smaller } \\
\text { in the subjects with } \\
\text { COVID-19. } \\
\end{array}$ & $\begin{array}{l}\text { COVID-19 infection } \\
\text { can have deleterious } \\
\text { effects on the } \\
\text { cochlear hair cells } \\
\text { in asymptomatic } \\
\text { subjects. The } \\
\text { mechanism of these } \\
\text { effects requires } \\
\text { further research. }\end{array}$ \\
\hline $\begin{array}{l}\text { Fidan, } \\
2020^{18}\end{array}$ & $\mathrm{C} / 4$ & Turkey & Case study & $\begin{array}{l}\text { A 35-year-old woman } \\
\text { with asymptomatic } \\
\text { COVID-19 (PCR-RT) } \\
\text { with a complaint of } \\
\text { otalgia and tinnitus }\end{array}$ & $\begin{array}{l}\text { PTA: Mild unilateral } \\
\text { (Right ear) conductive } \\
\text { hearing loss. } \\
\text { Tympanometry: Type } \\
\text { B on the right ear. }\end{array}$ & $\begin{array}{l}\text { Complete health } \\
\text { examinations must be } \\
\text { required for patients } \\
\text { with COVID-19 to find } \\
\text { the impairments }\end{array}$ \\
\hline
\end{tabular}

Captions: PTA: pure-tone threshold audiometry; TEOAE: transient evoked otoacoustic emissions.

Figure 3. Summary of the studies included in the integrative literature review 
The first study assessed 20 asymptomatic patients, aged 20 to 50 years, who tested positive for COVID-19 and underwent auditory assessment with pure-tone audiometry (PTA) and otoacoustic emissions. A significant increase in air-conduction auditory thresholds was observed in these people at the frequencies of 4000 , 6000 , and $8000 \mathrm{~Hz}$ in the PTA, as well as smaller mean response amplitude in the transient evoked otoacoustic emissions when compared with the control group which suggests impaired functioning of the cochlear hair cells ${ }^{8}$.

Therefore, based on the research question of this study, it should be highlighted in terms of physiopathology that the increase in air-conduction auditory thresholds occurred mainly at the high-frequency, basal region of the cochlea, though the values were not enough to indicate hearing loss (the thresholds were smaller than $25 \mathrm{~dB} \mathrm{HL}$ in all frequencies). Nonetheless, these findings point to worse auditory performance in people who had COVID-19 when compared with healthy individuals.

Another aspect to consider regarding the transient evoked otoacoustic emissions is that, even before those who acquired COVID-19 had their hearing loss evidenced in the PTA, there was a decrease in the size of the emission response when compared with healthy people. This finding is a characteristic revealed in this type of examination when the responses start to decrease or even be absent before changes take place in the PTA thresholds ${ }^{13}$.

Hence, this type of response found in the otoacoustic emissions is commonly seen in people exposed to agents that temporarily or permanently damage the cochlear structures. Thus, it can help the physician to stop the person's exposure to such ototoxic agents whenever possible ${ }^{13}$. Therefore, the findings in this study can be associated in the long run with sensorineural hearing loss, which is commonly found in viral diseases ${ }^{6}$.

Similar results to those observed in the COVID-19 patients ${ }^{8}$ is reported in other infectious diseases, which also presented smaller response amplitudes in the distortion-product otoacoustic emissions at multiple frequencies when compared with the control group ${ }^{14}$, supposing the SARS-CoV-2 can affect cochlear structures as well, especially the outer hair cells. This justifies these patients' need for audiological follow-up to provide adequate diagnosis and treatment.

There is a wide range of mechanisms that lead to hearing loss caused by different viruses. They can directly affect inner ear structures, such as the hair cells and the organ of Corti, either permanently or temporarily ${ }^{15,16}$.

Thus, it is important to know SARS-CoV-2's involvement with the infected patient's auditory system, besides unveiling whether it can cause congenital hearing loss via the transplacental transmission of the virus from the mother to the fetus, or even late hearing loss due to exposure to this virus. These situations point to the need for primary studies with cohort design ${ }^{17}$.

The second study included in this review reported the case of a 35-year-old asymptomatic COVID-19 female patient with no comorbidities, who complained of otalgia and tinnitus. The PTA revealed mild unilateral (right ear) conductive hearing loss, with a type B tympanometric curve on that side ${ }^{18}$.

Differently from the previous study, this one presents a case report of a woman with a unilateral change, with impairment in the middle ear, which consequently increased the air-conduction auditory thresholds. However, the sensory structures, measured with the bone-conduction auditory thresholds, were within normality standards. This suggests another type of impairment of the auditory structures other than the cochlea alone when COVID-19 occurs.

The viral hearing loss onset mechanisms, which include upper airway infections, can cause middle ear impairment, generating a conductive hearing loss. It differs from inner ear viral invasions, which can injure the cochlea and/or auditory nerve ${ }^{6,19}$.

Acute otitis media is preceded by a viral infection of the nasopharyngeal epithelium and auditory tube, and the bacterial colonization process in the nasopharynx only takes place when the virus begins inflammatory processes in this region ${ }^{20}$. Therefore, it is supposed that SARS-CoV-2, as well as other viruses, can cause greater susceptibility to opportunist infections in the middle ear, possibly due to a transitory decrease in the immune response to the infection, or even cause otitis due to the primary effects of the virus itself.

Furthermore, it should be noted that the studies included in this review ${ }^{8,18}$ assessed asymptomatic individuals regarding the disease, and the investigation of ototoxic effects for the treatment of symptomatic patients is necessary as well.

It is known that specialists throughout the world are searching for the best way to treat COVID-19 and discover the consequences caused by it. The data obtained in this review refer to two primary studies with limitations such as the small sample size, description 
of only asymptomatic cases, and the methodological designs (one was a case-control study and the other, a case report), thus pointing to subtle evidence concerning the results found. However, both studies excluded from the sample people with a previous history of hearing loss or associated comorbidities.

Hence, it is not yet possible to measure the dimensions of this new disease in such patients, neither in the symptomatic ones with other comorbidities. However, these recent reports already indicate a certain association between COVID-19 and the auditory system, which must be better investigated as new studies appear, with different methodologies and involving a greater number of participants.

\section{CONCLUSION}

The two studies included in this review showed different consequences of COVID-19 on hearing, with possible impairments on the sensory and mechanical structures of the auditory system. The knowledge on COVID-19 is limited, and further studies on its real impact on the auditory system are necessary.

\section{ACKNOWLEDGMENTS}

Gratitude is extended to the following institutions: Faculdade de Medicina de Botucatu and Universidade Federal de Santa Catarina, for their technical support.

\section{REFERENCES}

1. Li YC, Bai WZ, Hashikawa T. The neuroinvasive potential of SARS-CoV2 may play a role in the respiratory failure of COVID-19 patients. J Med Virol. 2020;92(6):552-5.

2. Sriwijitalai W, Wiwanitkit V. COVID-19 outbreak in international airport - Where the incidence case occurs? Int J Prev Med. 2020;11(1):51.

3. Chen N, Zhou M, Dong X, Qu J, Gong F, Han Y et al. Epidemiological and clinical characteristics of 99 cases of 2019 novel coronavirus pneumonia in Wuhan, China: a descriptive study. Lancet. 2020;395(10223):507-13.

4. Zhai $P$, Ding $Y$, Wu X, Long J, Zhong Y, Li Y. The epidemiology, diagnosis and treatment of COVID-19. Int J Antimicrob Agents. 2020;55(5):105955.
5. Opening speech by the Director-General of WHO, without information from COVID-19. In: WHO [Internet]. [accessed on March 11, 2020]. Available at: https://www.who.int/dg/speeches/detail/whodirector-general-s-opening-remarks-at-the-mediabriefing-on-covid-19\%2D\%2D-11- March 2020.

6. Vieira $A B C$, Mancini $P$, Gonçalves DU. Doenças infecciosas e perda auditiva. Rev Med Minas Gerais. 2010;20(1):102-6.

7. Demmler GJ. Screening for congenital cytomegalovirus infection: a tapestry of controversies. J Pediatr. 2005;146(2):162-4.

8. Mustafa MWM. Audiological profile of asymptomatic Covid-19 PCR-positive cases. Am J Otolaryngol. 2020;41(3):102483.

9. Canto GDL, Réus JC. Mãos à obra. In: Violin GC (ed). Revisões Sistemáticas da Literatura: Guia Prático. 1a edição. Curitiba: Brazil Publishing; 2020. p. 24-6.

10. Vosgerau DSR, Romanowsk JP. Estudos de revisão: implicações conceituais e metodológicas. Rev. Diálogo Educ. 2014;14(41):165-89.

11. Honório HM, Satiago Júnior JF. Revisões sistemáticas: definições, importância e limitações. In: Honório HM, Santiago Júnior JF (orgs). Fundamentos das revisões sistemáticas. 1a edição. São Paulo: Quintessence Editora; 2018. p. 3-21.

12. Howick J. Oxford Centre for Evidence-based Medicine-Levels of Evidence. [Internet] 2011. Available at: http://www.cebm.net/index. aspx?o $=5653$.

13. Lord SG. Monitoring protocols for cochlear toxicity. Semin Hear. 2019;40(2):122-43.

14. Maro II, Fellow AM, Clavier OH, Gui J, Rieke CC, Wilbur JC et al. Auditory impairments in HIV-infected children. Ear Hear. 2016;37(4):443-51.

15. Guo J, Chai R, Li H, Sun S. Protection of hair cells from ototoxic drug-induced hearing loss. Adv Exp Med Biol. 2019;1130:17-36.

16. Michels TC, Duffy MT, Rogers DJ. Hearing loss in adults: differential diagnosis and treatment. Am Fam Physician. 2019;100(2):98-108.

17. Cohen BE, Durstenfeld A, Roehm PC. Viral causes of hearing loss: a review for hearing health professionals. Trends Hear. 2014;29(18):1-17.

18. Fidan V. New type of coronavirus induced acute otitis media in adult. Am $\mathrm{J}$ Otolaryngol. In press 2020. 
19. Cohen BE, Durstenfeld A, Roehm PC. Viral causes of hearing loss: a review for hearing health professionals. Trends Hear. 2014;18:1-17.

20. Nokso-Koivisto J, Marom T, Chonmaitree $T$. Importance of viruses in acute otitis media. Curr. Opin. Pediatr. 2015;27(1):110-5. 